This is a self-archived version of an original article. This version may differ from the original in pagination and typographic details.

Author(s): Lahtinen, Elmeri; Turunen, Lotta; Hänninen, Mikko M.; Kolari, Kalle; Tuononen,
Heikki M.; Haukka, Matti

Title: Fabrication of Porous Hydrogenation Catalysts by a Selective Laser Sintering 3D Printing Technique

Year: 2019

Version: Published version

Copyright: @ 2019 American Chemical Society

Rights: CC BY 4.0

Rights url: https://creativecommons.org/licenses/by/4.0/

Please cite the original version:

Lahtinen, E., Turunen, L., Hänninen, M. M., Kolari, K., Tuononen, H. M., \& Haukka, M. (2019).

Fabrication of Porous Hydrogenation Catalysts by a Selective Laser Sintering 3D Printing

Technique. ACS Omega, 4(7), 12012-12017. https://doi.org/10.1021/acsomega.9b00711 


\title{
Fabrication of Porous Hydrogenation Catalysts by a Selective Laser Sintering 3D Printing Technique
}

\author{
Elmeri Lahtinen, ${ }^{\circledR}$ Lotta Turunen, Mikko M. Hänninen, Kalle Kolari, Heikki M. Tuononen, \\ and Matti Haukka*(i) \\ Department of Chemistry, University of Jyväskylä, P.O. Box 35, FI-40014 Jyväskylä, Finland
}

Supporting Information

\begin{abstract}
Three-dimensional selective laser sintering printing was utilized to produce porous, solid objects, in which the catalytically active component, $\mathrm{Pd} / \mathrm{SiO}_{2}$, is attached to an easily printable supporting polypropylene framework. Physical properties of the printed objects, such as porosity, were controlled by varying the printing parameters. Structural characterization of the objects was performed by helium ion microscopy, scanning electron microscopy, and X-ray tomography, and the catalytic performance of the objects was tested in the hydrogenation of styrene, cyclohexene, and phenylacetylene. The results show that the selective laser sintering process provides an alternative and effective way to produce highly active and easily reusable heterogeneous catalysts without significantly reducing the catalytic efficiency of the active $\mathrm{Pd} / \mathrm{SiO}_{2}$ component. The ability to control the size, porosity, mechanical properties, flow properties, physical properties, and chemical properties of the catalyst objects opens up possibilities to optimize devices for different reaction environments including batch reactions and continuous flow systems.
\end{abstract}

\section{INTRODUCTION}

During the last decade, interest in utilizing additive manufacturing for a wide variety of applications has increased rapidly. ${ }^{1-5}$ This has also fueled the development of threedimensional (3D) printing as one of the most promising technologies in the preparation of multifunctional and effective catalysts, ${ }^{6,7}$ Recently, techniques such as fused deposition modeling or direct ink writing have been used to fabricate active catalysts. ${ }^{8,9}$ In addition to these extrusion-based methods, stereolithography has been used to produce catalysts for multistep reactions. ${ }^{10}$ Furthermore, 3D printing has been exploited in the preparation of highly sophisticated reactors and reactionware that have the catalytically active material directly embedded in their structures. ${ }^{11,12}$ However, despite all of the aforementioned advances, most of the previously used 3D printing-based techniques require postprocessing of the printed objects and/or synthesis of multicomponent printing materials with specific physical properties to obtain the final catalytically active object. Such steps significantly limit the usability of 3D printing for catalyst manufacturing in practice.

Selective laser sintering (SLS) is one of the most commonly used industrial 3D printing techniques, but it is currently practically unutilized for the preparation of structured catalysts. In a typical SLS process, a $\mathrm{CO}_{2}$ laser is used to sinter polymer powder to the desired physical form by partially or completely melting particles in order to fuse them together. If the particles are sintered in such a way that their surfaces are only partially melted, a solid structure containing accessible voids between the sintered grains is obtained. Furthermore, by adjusting the printing conditions, ${ }^{13-16}$ the porosity, as well as other physical and mechanical properties, of the printed object can be controlled and even adjusted differently within different sections of the object. ${ }^{17}$ Such objects can be utilized directly in chemical applications. For example, if a porous column is printed, a fluid (liquid or gas) can flow through the object, interacting with the surface of the partially fused particles. ${ }^{17} \mathrm{By}$ mixing a chemically active component into an easily printable polymer matrix, a range of chemically functional objects can be prepared. 3D printing opens up possibilities to design and manufacture objects that not only exhibit desired catalytic properties but also meet specific physical and mechanical requirements set by the reaction environment.

The advantages that porous SLS 3D-printed objects offer are obvious when compared with typical powder-based catalysts. Catalyst powders are commonly used in batch reactors where they must be carefully filtered off after the catalytic reaction has taken place. Another option is to pack the powder in a column and use it in a continuous flow reactor. In the latter case, particular care must be taken when packing the powder to prevent excessive channeling and formation of ineffective regions in the reactor. However, it is always possible that some channeling occurs when the reaction solution runs through the column. In contrast, if the particles are sintered together by $3 \mathrm{D}$ printing, channeling becomes impossible and the catalyst can be easily recovered from the reaction vessel and reused.

Recently, we have shown that SLS 3D printing can be used to fabricate solid but porous flow-through filters for selective capturing of $\mathrm{Au}, \mathrm{Pd}$, and $\mathrm{Pt}$ from acidic leachate of electronic waste. $^{17,98}$ In this paper, we utilized the SLS technique to produce printed heterogeneous hydrogenation catalyst for lab-

Received: March 14, 2019

Accepted: July 1, 2019

Published: July 11, 2019 
scale batch reactions. The printing material used in the work is a mixture of commercially available $\mathrm{Pd} / \mathrm{SiO}_{2}$ powder and polypropylene (PP). The impact of the porous structure of the printed objects on the catalytic activity was studied using advanced imaging technology, while the hydrogenation activity of the 3D-printed catalyst is demonstrated by performing a series of catalytic reactions in a batch reactor.

\section{RESULTS AND DISCUSSION}

Palladium on silica ( $\mathrm{Pd} / \mathrm{SiO}_{2}$ with 5 wt $\%$ palladium) was selected as the active component of the hybrid printing material because of its well-known catalytic activity, high surface area, and good thermal durability. ${ }^{19,20}$ On the other hand, the highly inert PP was used as the supporting polymer matrix as it is a fully saturated hydrocarbon, which allows also reductive chemical reactions, such as hydrogenation, to be performed without the risk of decomposition of the polymer framework itself. Loading of 10 wt $\%$ of the $\mathrm{Pd} / \mathrm{SiO}_{2}$ component was mixed into the supporting PP powder, resulting in a powder mixture for SLS printing that contained 0.5 wt $\%$ of palladium. The concentration of palladium in the SLS 3D-printed stir bar sleeves was confirmed by using microwave-assisted leaching, followed by ICP-OES analysis (Table S1).

Catalytic reactions were carried out in an autoclave as batch reactions. The catalysts were introduced to the system as 3Dprinted magnetic stir bar covers (Figure 1). This provides a

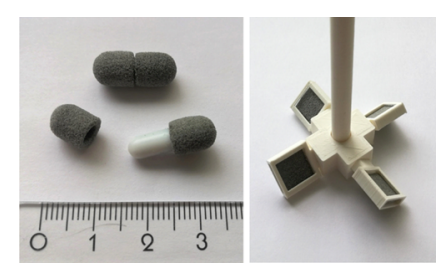

Figure 1. Left: SLS 3D-printed stir bar sleeves (diameter of $6.5 \mathrm{~mm}$ and length of $8.5 \mathrm{~mm}$ ) used in hydrogenation experiments. Right: A concept of an alternative catalysts design for the mechanical stirrer. ${ }^{21}$

simple and practical way to use catalysts in lab-scale reactors. We underline that when using SLS 3D printing, the catalytic object can be of any shape or size, and therefore can be tailormade for different types of batch reactors or shaped as a flowthrough object for continuous flow reactors. By carefully finetuning the $3 \mathrm{D}$ printing parameters, such as laser power, printing rate, and the printing temperature, a porous object with good mechanical properties, such as durability, hardness, and rigidity, can be fabricated. After experimenting with various settings, an optimal combination of parameters was found (Experimental Details) and used for all printed catalysts. When considering stir bar covers, the catalytic object must be rigid enough to stay firmly around the stir bar during the reactions. Hardness and durability are also crucial as the printed covers need to resist abrasive forces that take place not only during stirring but also during cleaning. In our system, no detectable wearing or breakage of the catalytic objects was observed, thus, showing their ability to withstand mechanical stress caused by the stirring.

The nonconducting nature of the used $\mathrm{PdSiO}_{2} / \mathrm{PP}$ material prevented the use of traditional imaging by scanning electron microscopy (SEM). However, this problem was solved by using helium ion microscopy (HIM), where the charging effect of helium cations is neutralized by a low-voltage electron beam.
With this technique, even highly sensitive and insulating materials like biological samples can be accurately imaged without any loss of image quality. ${ }^{22}$ First, a HIM image of a pure SLS 3D-printed PP was taken to confirm the resulting porous structure generated by the voids between the partially melted polymer beads (Figure 2a). Similar porosity is also
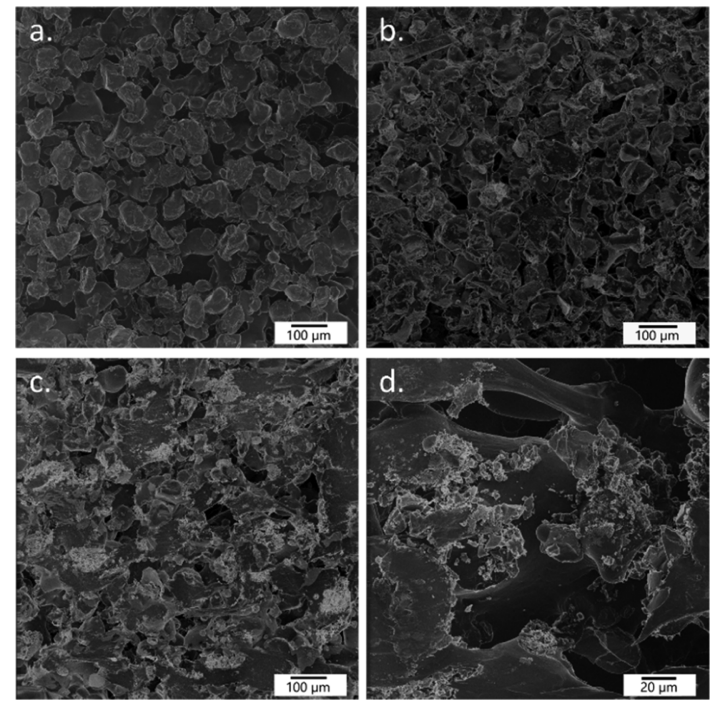

Figure 2. HIM images of the break surface of SLS 3D-printed pure PP (a) and top and break surfaces of SLS 3D-printed stir bar covers (bd). The $\mathrm{Pd} / \mathrm{SiO}_{2}$ catalyst can be seen as pale colored areas with sharp edges in images $(b-d){ }^{21}$

evident in the HIM images of the top and break surfaces of the $3 \mathrm{D}$-printed stir bar covers containing 10 wt $\%$ of $\mathrm{Pd} / \mathrm{SiO}_{2}$ (Figure $2 \mathrm{~b}-\mathrm{d}$ ). In the latter case, the additive $\mathrm{Pd} / \mathrm{SiO}_{2}$ is clearly visible as pale colored areas with sharp edges. Furthermore, the top and break surface images show that the additive is evenly distributed and firmly attached only on the surface of the PP matrix. Thus, the catalytically active component is not capsulated inside the melted polymer and therefore remains available for catalytic reactions. The porosity and the dispersion of $\mathrm{SiO}_{2}$ particles within the 3D-printed objects was also confirmed by using X-ray tomography and SEM-energy-dispersive system (EDS) analysis which further showed the even distribution of the particles (Figures S1-S4 and Table S2)

Thermal analysis of the 3D-printed stir bar covers containing 10 wt $\%$ of $\mathrm{Pd} / \mathrm{SiO}_{2}$ was conducted using thermogravimetry and differential thermal analysis (TG/DTA) (Figure S5). The results show that there is a mass change of roughly $-88 \%$ as the temperature is increased to $500{ }^{\circ} \mathrm{C}$, after which only a minimal change in the mass of the sample is observed. Thus, the thermal behavior of the hybrid $\mathrm{PdSiO}_{2} / \mathrm{PP}$ material is fully comparable to that of pure PP plastic. ${ }^{23}$ Because of the high thermal stability of the active silica-supported palladium, it did not have any impact on the thermal behavior of the printed object within the analyzed thermal range. Further characterization of the $\mathrm{PdSiO}_{2} / \mathrm{PP}$ was also carried out by conducting powder X-ray diffraction (PXRD) measurement of the material. The analysis clearly shows the characteristics peaks of $\mathrm{PP}$ and $\mathrm{Pd}$, while $\mathrm{SiO}_{2}$ is not clearly visible. This is probably due to the amorphous nature of the $\mathrm{SiO}_{2}$. It is also plausible that the peaks are masked by the dominating PP peaks (Figure S6). Additionally, Fourier transform infrared (FTIR) was used 
Table 1. Reactions of Styrene, Cyclohexene, and Phenylacetylene Catalyzed with Both 3D-Printed Catalyst Stir bar Sleeves and the Powdery $\mathrm{Pd} / \mathrm{SiO}_{2}$ Catalyst $^{21}$

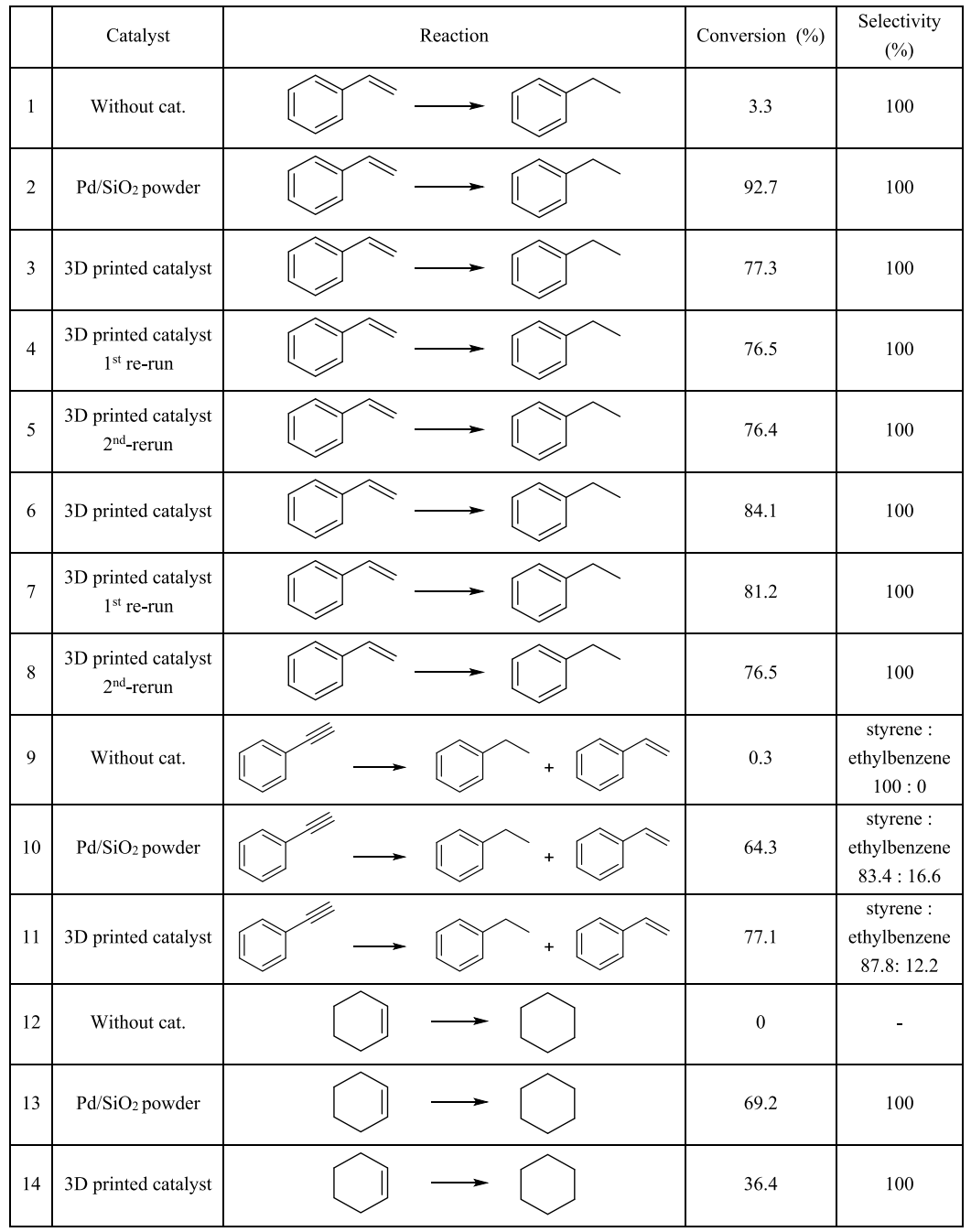

to monitor for any changes in the PP network prior to and after the printing process (Figures S7-S9). No detectable changes were observed.

The catalytic activity of the 3D-printed stir bar covers containing 10 wt $\%$ of $\mathrm{Pd} / \mathrm{SiO}_{2}$ was tested in hydrogenation reactions. Styrene, cyclohexene, and phenylacetylene were chosen as substrates to test different types of unsaturated hydrocarbons. The reactions were performed in a Teflon-lined autoclave under a hydrogen pressure of 10 bar at room temperature for $2 \mathrm{~h}$. The catalyst loading in the reaction mixture was adjusted to $0.1 \mathrm{~mol} \%$ in each case and the performance of the printed catalyst was compared with the nonprinted $\mathrm{Pd} / \mathrm{SiO}_{2}$ powder to study the impact of the printing process on the activity of the catalyst. The resulting reaction mixtures were analyzed using gas chromatography (GC) and the results are summarized in Table 1.

The results in Table 1 show that the $3 \mathrm{D}$-printed catalyst is able to catalyze the hydrogenation of the chosen substrates effectively. A comparison of the data to that obtained for the nonprinted $\mathrm{Pd} / \mathrm{SiO}_{2}$ powder shows that $3 \mathrm{D}$ printing has only a minor effect on the total activity in the case of styrene and phenylacetylene. For styrene, a $92.7 \%$ conversion was obtained with nonprinted pure $\mathrm{Pd} / \mathrm{SiO}_{2}$ powder (Table 1 , reaction 2 ), while a 3D-printed stir bar cover gave a $76.7 \%$ conversion under the same conditions (Table 1, average of reactions 3-5). In the case of phenylacetylene, the 3D-printed catalyst even achieved a slightly better conversion (Table 1 , reaction 11) than the nonprinted $\mathrm{Pd} / \mathrm{SiO}_{2}$ powder (Table 1 , reaction 10), 77.1 and $64.3 \%$, respectively. These data show that the catalytically active component in the printed object is well achievable by styrene and phenylacetylene. However, when cyclohexene was used as the substrate (Table 1 , reactions 13 and 14), the nonprinted powdery catalyst performed considerably better than the 3D-printed catalyst with a conversion of $69.2 \%$ versus $36.4 \%$. This is most likely due to the more sterically hindered double bond in cyclohexene, which affects its ability to interact with the active catalyst inside the pores of the supporting PP matrix. It should be noted that the structure of the $3 \mathrm{D}$-printed catalyst was not optimized for any particular substrate. Therefore, a higher conversion could be achieved by optimization of the porous structure of the catalyst. Alternatively, the difference in activity between the powder and 3D-printed catalysts could be compensated, at least partially, by adjusting the reaction conditions.

Reusability of the 3D-printed catalyst was tested in three consecutive runs by using the styrene substrate (Table 1, reactions 3-5). Nearly identical conversions, ranging from 76.4 to $77.3 \%$, demonstrate the constant behavior of the 
Table 2. Total Amount of Palladium Leached into Reaction Mixture During Catalytic Reactions When Using Either 3DPrinted or Powderous $\mathrm{Pd} / \mathrm{SiO}_{2}$ Catalyst $^{a}$

\begin{tabular}{|c|c|c|}
\hline Catalyst & Reaction & $\begin{array}{l}\text { Total amount of palladium } \\
\text { leached from the catalyst } \\
\text { (wt- } \% \text { ) }\end{array}$ \\
\hline $\begin{array}{c}\mathrm{Pd} / \mathrm{SiO}_{2} \text { pow- } \\
\text { der }\end{array}$ & & 0.02 \\
\hline $\begin{array}{l}\text { 3D printed } \\
\text { catalyst }\end{array}$ & & 0.30 \\
\hline $\begin{array}{l}\text { 3D printed } \\
\text { catalyst } \\
\text { 1. reuse }\end{array}$ & & 0.02 \\
\hline $\begin{array}{l}\text { 3D printed } \\
\text { catalyst } \\
\text { 2. reuse }\end{array}$ & & 0.09 \\
\hline $\begin{array}{c}\mathrm{Pd} / \mathrm{SiO}_{2} \text { pow- } \\
\text { der }\end{array}$ & & 0.74 \\
\hline $\begin{array}{l}\text { 3D printed } \\
\text { catalyst }\end{array}$ & & 0.57 \\
\hline $\begin{array}{c}\mathrm{Pd} / \mathrm{SiO}_{2} \text { pow- } \\
\text { der }\end{array}$ & & 0.06 \\
\hline $\begin{array}{l}\text { 3D printed } \\
\text { catalyst }\end{array}$ & & 0.10 \\
\hline
\end{tabular}

${ }^{a_{T}}$ The amount of palladium is calculated by comparing the amount of leached palladium to the mass of the palladium present in the used catalyst.

catalyst. However, the freshly printed objects must be carefully cleaned before use, to remove any residual, unsintered material. Need for this arises because of the SLS technique, where the powder bed is supporting the forming object during printing and the object is formed inside the powder bed and is therefore covered with an unsintered material. ${ }^{24}$ The entries 6-8 in Table 1 , show the impact of insufficient cleaning. The conversion of $84.1 \%$ was obtained when a fresh catalyst was used. The conversion in the second run was $81.2 \%$ and the final activity of $76.5 \%$ was obtained only in the third run after residual unsintered material was completely lost during the first two runs.

Leaching of palladium from the 3D-printed catalysts was investigated under two different environments. First, samples from reaction mixtures from catalytic runs were analyzed using ultrasound-assisted acidic leaching, to dissolve any palladium particles present, after which the amount of palladium was analyzed using inductively coupled plasma optical emission spectrometry (ICP-OES). The analyses showed that under actual reaction conditions, only roughly 0.10 to $0.57 \mathrm{wt} \%$ of the palladium present in the fresh 3D-printed stir bar sleeves was leached to the reaction mixture (Table 2). For comparison, a similar leaching behavior was observed also with the unprinted $\mathrm{Pd} / \mathrm{SiO}_{2}$ powder (Table 2). This means that a certain amount of $\mathrm{Pd}$ was leached from the active $\mathrm{Pd} /$ $\mathrm{SiO}_{2}$ component whether it was printed or not. However, it was also observed that in some cases when the printed catalysts were reused several times, leaching of Pd was higher when the freshly printed catalyst was used. As already discussed, this is due to a small amount of residual, unsintered material that was released during the first run. After the loss of the unsintered material, leaching was considerably lowered and at the same level as leaching from $\mathrm{Pd} / \mathrm{SiO}_{2}$ powder. In fact, in some cases printing may even protect the catalysts reducing the amount of the leached catalyst.

The anchoring of $\mathrm{Pd} / \mathrm{SiO}_{2}$ to the supporting polymer was also tested by placing the stir bar covers onto a stirring bar that was stirred vigorously in boiling water for $60 \mathrm{~min}$. Samples of the resulting solutions were again taken and analyzed using ultrasound-assisted acidic leaching in combination with ICPOES. The results showed that only $0.26 \mathrm{wt} \%$ of the total amount of palladium present in the $3 \mathrm{D}$-printed catalysts was leached into the boiling water, which illustrates that the catalytically active $\mathrm{Pd} / \mathrm{SiO}_{2}$ is firmly attached to the supporting matrix. The results also demonstrate the good abrasion resistance of the 3D-printed stir bar covers as no noticeable wearing was seen during the experiments.

\section{CONCLUSIONS}

We have shown that SLS 3D printing can be utilized to produce porous, efficient, easy-to-use, and reusable heterogeneous hydrogenation catalysts from a mixture of $\mathrm{Pd} / \mathrm{SiO}_{2}$ powder and PP beads. The manufactured catalytic objects were simple stir bar covers suitable for lab-scale batch reactions, but the same printing technique can be easily scaled up to fabricate tailor-made catalytically active objects for other type of reactors and reaction environments. The results also showed that the employed printing process does not have a significant impact on the catalytic performance of the catalytically active additive. Furthermore, SLS sets only minimal requirements for the printing materials, and both the catalytically active component, as well as the supporting matrix, can be altered in almost any fashion imaginable. The printed catalytic objects showed good thermal and mechanical properties along with good resistance to leaching of the catalytically active palladium metal. We 
believe that $3 \mathrm{D}$-printing can change the way we produce our catalysts in the future.

\section{EXPERIMENTAL DETAILS}

Chemicals and Materials. All organic reagents and solvents were purchased from Merck and used as received without any additional drying. Palladium on silica (Escat 1351) was purchased from Strem and used as received. PP was obtained from ADVANC3D materials and used without any additional pretreatment.

3D Printing of the Catalytic Objects. The catalysts objects were printed with the Sharebot SnowWhite SLS 3D printer. The printing material was prepared by mixing 10 wt $\%$ of commercial supported $\mathrm{Pd} / \mathrm{SiO}_{2}(5 \%$ of $\mathrm{Pd}$ ) catalyst powder with commercial PP powder (particle size $50 \mu \mathrm{m}$ ). Highly porous and durable objects with a diameter of $6.5 \mathrm{~mm}$ and length of $8.5 \mathrm{~mm}$ (Figure 1) were obtained using following printing parameters: powder temperature: $122{ }^{\circ} \mathrm{C}$, $40 \%$ laser power (14 W, CO 2 laser), $64000 \mathrm{pps}\left(2560 \mathrm{~mm} \mathrm{~s}^{-1}\right.$ ) laser speed and $0.1 \mathrm{~mm}$ layer height. The $3 \mathrm{D}$-printed objects were thoroughly cleaned of any nonsintered powder after the printing process. The objects were further cleansed by stirring them in water for 10 min before any catalysis runs.

Catalytic Studies. In each reaction, $7 \mathrm{mmol}$ of the substrate, styrene, cyclohexene, or phenylacetylene was introduced into a Teflon-lined autoclave with $2 \mathrm{~mL}$ of methanol and the stir bar equipped with the catalyst sleeves. The total Pd loading was adjusted to $0.1 \mathrm{~mol} \%$ for each reaction. Hydrogenation reactions were performed under 10 bar hydrogen pressure at room temperature. The reaction time was $2 \mathrm{~h}$. Same reaction conditions were used also for the pure, nonprinted $\mathrm{Pd} / \mathrm{SiO}_{2}$ powder.

Gas Chromatography. The samples were analyzed using the Agilent 7820A GC system equipped with Agilent HP-5 column. GC samples were taken directly from the reaction mixture, diluted with dichloromethane and analyzed without further processing of the sample.

Palladium Leaching Studies. Palladium content of the reaction products was analyzed by placing $1 \mathrm{~mL}$ of the reaction mixture into $10 \mathrm{~mL}$ digestion tube along with $1 \mathrm{~mL}$ of aqua regia. Ultrasound-assisted digestion ( 6 times $5 \mathrm{~min}$ at $60{ }^{\circ} \mathrm{C}$ ) was performed. The sample was then diluted and analyzed using PerkinElmer 8300 ICP-OES using procedure further discussed in the Supporting Information. The results are presented in Table 2. Mechanical binding of the $\mathrm{Pd} / \mathrm{SiO}_{2}$ into the $3 \mathrm{D}$-printed objects was studied by placing the catalyst sleeves on a stir bar and inserting them into $10 \mathrm{~mL}$ of boiling water for $60 \mathrm{~min}$. After stirring the solution vigorously for 60 $\mathrm{min}$, the stir bar was removed. Aqua regia $(5 \mathrm{~mL})$ was added into the water and ultrasound-assisted leaching (6 times $5 \mathrm{~min}$ at $60{ }^{\circ} \mathrm{C}$ ) was performed to dissolve any palladium particles present in the solution. About $0.26 \%$ of the total amount of palladium present in the $3 \mathrm{D}$-printed catalyst sleeves was found to have leached into the water after the experiment.

For the ICP-OES analyses, argon gas flow of $15 \mathrm{~mL} / \mathrm{min}$ was used with a sample flow rate of $1.5 \mathrm{~L} \mathrm{~min}^{-1}$, nebulizer gas flow of $0.7 \mathrm{~L} \mathrm{~min}^{-1}$ and auxiliary gas flow of $0.2 \mathrm{~L} \mathrm{~min}^{-1}$. RF power of $1500 \mathrm{~W}$ was used. Calibration standards were prepared by diluting PerkinElmer $1000 \mathrm{mg} \mathrm{L}^{-1}$ spectroscopy standard. Palladium was analyzed using a wavelength of $340.458 \mathrm{~nm}$.

Helium Ion Microscopy. Imaging was performed with a Carl Zeiss ORION NanoFab helium ion microscope. The beam energy used was $30 \mathrm{keV}$ and the beam was set between 0.31 and $0.32 \mathrm{pA}$. Dwell time of $0.2 \mu$ s was used for the scans with a working distance of $8.4 \mathrm{~mm}$. Samples were not treated in any way before imaging aside from the use of pressurized air to clear any remaining loose particles from the surfaces of the samples.

Powder X-ray Diffraction. X-ray powder diffraction data were acquired by the PANalytical X'Pert PRO diffractometer in Bragg-Brentano geometry using $\mathrm{Cu} \mathrm{K} \alpha_{1}$ radiation (Johannsson type monochromator, $\lambda=1.5406 \AA$, $45 \mathrm{kV}, 40$ $\mathrm{mA})$. The sample was prepared with a back-load technique into a shallow cavity ( $28 \mathrm{~mm}$ diameter) on a steel made sample holder. The data was recorded from a spinning sample by a $X$ 'Celerator detector using continuous scanning mode in the $2 \theta$ range of $6^{\circ}-90^{\circ}$ with a step size of $0.017^{\circ}$ and counting time of $400 \mathrm{~s}$ per step ( $4 \mathrm{~h} 30 \mathrm{~min}$ overall time). Diffraction data were processed with the Malvern PANalytical HighScore Plus v. 4.7 program.

\section{ASSOCIATED CONTENT}

\section{S Supporting Information}

The Supporting Information is available free of charge on the ACS Publications website at DOI: 10.1021/acsomega.9b00711.

X-ray tomography image and SEM-EDS results of the catalyst; TG/DTA results for the 3D-printed catalyst; PXRD pattern of the $\mathrm{PdSiO}_{2} / \mathrm{PP}$ material; FTIR spectra of the PP before and after printing; and ICP-OES results for the determination of the palladium concentration (PDF)

\section{AUTHOR INFORMATION}

\section{Corresponding Author}

*E-mail: matti.o.haukka@jyu.fi.

\section{ORCID}

Elmeri Lahtinen: 0000-0002-8414-9915

Heikki M. Tuononen: 0000-0002-4820-979X

Matti Haukka: 0000-0002-6744-7208

\section{Author Contributions}

M.H. conceptualized the idea of using SLS 3D printing for catalyst preparation. E.L. and M.M.H. carried out the designing, modeling and $3 \mathrm{D}$ printing of the stir bar sleeves. E.L., L.T. and K.K. performed the catalytic studies. M.H. supervised the work with the support of H.M.T. Paper was written jointly by E.L., L.T., M.M.H., H.M.T. and M.H.

\section{Notes}

The authors declare no competing financial interest.

\section{ACKNOWLEDGMENTS}

Financial support received from the Centennial Foundation of Technology Industries of Finland and Jane and Aatos Erkko foundation is greatly appreciated. The research was also supported by the Academy of Finland [grant nos: 295581 (M.H.) and 282499 (H.M.T.)] and by the University of Jyväskylä. Authors wish to thank Dr. Kimmo Kinnunen for performing the HIM experiments, Dr. Sara Durini for performing the TG/DTA analysis and Dr. Manu Lahtinen for the PXRD analysis. Authors would also like to acknowledge the services of the Helsinki University X-ray micro-imaging laboratory for the X-ray tomography and University of Eastern Finland for the SEM-EDS analyses. 


\section{REFERENCES}

(1) Kotz, F.; Arnold, K.; Bauer, W.; Schild, D.; Keller, N.; Sachsenheimer, K.; Nargang, T. M.; Richter, C.; Helmer, D.; Rapp, B. E. Three-Dimensional Printing of Transparent Fused Silica Glass. Nature 2017, 544, 337-339.

(2) Foo, C. Y.; Lim, H. N.; Mahdi, M. A.; Wahid, M. H.; Huang, N. M. Three-Dimensional Printed Electrode and Its Novel Applications in Electronic Devices. Sci. Rep. 2018, 8, 7399.

(3) Kong, Y. L.; Tamargo, I. A.; Kim, H.; Johnson, B. N.; Gupta, M. K.; Koh, T.-W.; Chin, H.-A.; Steingart, D. A.; Rand, B. P.; McAlpine, M. C. 3D Printed Quantum Dot Light-Emitting Diodes. Nano Lett. 2014, 14, 7017-7023.

(4) Gupta, M. K.; Meng, F.; Johnson, B. N.; Kong, Y. L.; Tian, L.; Yeh, Y.-W.; Masters, N.; Singamaneni, S.; McAlpine, M. C. 3D Printed Programmable Release Capsules. Nano Lett. 2015, 15, 53215329.

(5) Foster, C. W.; Down, M. P.; Zhang, Y.; Ji, X.; Rowley-Neale, S. J.; Smith, G. C.; Kelly, P. J.; Banks, C. E. 3D Printed Graphene Based Energy Storage Devices. Sci. Rep. 2017, 7, 42233.

(6) Hurt, C.; Brandt, M.; Priya, S. S.; Bhatelia, T.; Patel, J.; Selvakannan, P.; Bhargava, S. Combining Additive Manufacturing and Catalysis: A Review. Catal. Sci. Technol. 2017, 7, 3421-3439.

(7) Parra-Cabrera, C.; Achille, C.; Kuhn, S.; Ameloot, R. 3D Printing in Chemical Engineering and Catalytic Technology: Structured Catalysts, Mixers and Reactors. Chem. Soc. Rev. 2018, 47, 209-230.

(8) Zhou, X.; Liu, C.-j. Three-dimensional Printing for Catalytic Applications: Current Status and Perspectives. Adv. Funct. Mater. 2017, 27, 1701134

(9) Díaz-Marta, A. S.; Tubío, C. R.; Carbajales, C.; Fernández, C.; Escalante, L.; Sotelo, E.; Guitián, F.; Barrio, V. L.; Gil, A.; Coelho, A. Three-Dimensional Printing in Catalysis: Combining 3D Heterogeneous Copper and Palladium Catalysts for Multicatalytic Multicomponent Reactions. ACS Catal. 2018, 8, 392-404.

(10) Manzano, J. S.; Weinstein, Z. B.; Sadow, A. D.; Slowing, I. I. Direct 3D Printing of Catalytically Active Structures. ACS Catal. 2017, 7, 7567-7577.

(11) Kitson, P. J.; Marie, G.; Francoia, J.-P.; Zalesskiy, S. S.; Sigerson, R. C.; Mathieson, J. S.; Cronin, L. Digitization of Multistep Organic Synthesis in Reactionware for On-Demand Pharmaceuticals. Science 2018, 359, 314-319.

(12) Avril, A.; Hornung, C. H.; Urban, A.; Fraser, D.; Horne, M.; Veder, J.-P.; Tsanaktsidis, J.; Rodopoulos, T.; Henry, C.; Gunasegaram, D. R. Continuous Flow Hydrogenations Using Novel Catalytic Static Mixers inside a Tubular Reactor. React. Chem. Eng. 2017, 2, 180-188.

(13) Gibson, I.; Shi, D. Material Properties and Fabrication Parameters in Selective Laser Sintering Process. Rapid Prototyp. J. 1997, 3, 129-136.

(14) Shirazi, S. F. S.; Gharehkhani, S.; Mehrali, M.; Yarmand, H.; Metselaar, H. S. C.; Adib Kadri, N.; Osman, N. A. A. A Review on Powder-Based Additive Manufacturing for Tissue Engineering: Selective Laser Sintering and Inkjet 3D Printing. Sci. Technol. Adv. Mater. 2015, 16, 033502.

(15) Fina, F.; Goyanes, A.; Gaisford, S.; Basit, A. W. Selective Laser Sintering (SLS) 3D Printing of Medicines. Int. J. Pharm. 2017, 529, 285-293.

(16) Lahtinen, E.; Precker, R.; Lahtinen, M.; Hey-Hawkins, E.; Haukka, M. Selective Laser Sintering of Metal-Organic Frameworks: Production of Highly Porous Filters by 3D Printing onto a Polymeric Matrix. Chempluschem 2019, 84, 222-225.

(17) Lahtinen, E.; Hänninen, M. M.; Kinnunen, K.; Tuononen, H. M.; Väisänen, A.; Rissanen, K.; Haukka, M. Porous 3D Printed Scavenger Filters for Selective Recovery of Precious Metals from Electronic Waste. Adv. Sustainable Syst. 2018, 2, 1800048.

(18) Lahtinen, E.; Kivijärvi, L.; Tatikonda, R.; Väisänen, A.; Rissanen, K.; Haukka, M. Selective Recovery of Gold from Electronic Waste Using 3D-Printed Scavenger. ACS Omega 2017, 2, 7299-7304.
(19) Polshettiwar, V.; Len, C.; Fihri, A. Silica-Supported Palladium: Sustainable Catalysts for Cross-Coupling Reactions. Coord. Chem. Rev. 2009, 253, 2599-2626.

(20) Opanasenko, M.; Štěpnička, P.; Čejka, J. Heterogeneous Pd Catalysts Supported on Silica Matrices. RSC Adv. 2014, 4, 6513765162 .

(21) Haukka, M.; Väisänen, A.; Rissanen, K.; Lahtinen, E.; Kivijärvi, L. A Porous Body, Method For Manufacturing It And Its Use For Collecting Substance From Source Material. WO/2019/008232. FIN Pat. Appl. No. 20186003, 2018.

(22) Joens, M. S.; Huynh, C.; Kasuboski, J. M.; Ferranti, D.; Sigal, Y. J.; Zeitvogel, F.; Obst, M.; Burkhardt, C. J.; Curran, K. P.; Chalasani, S. H.; et al. Helium Ion Microscopy (HIM) for the Imaging of Biological Samples at Sub-Nanometer Resolution. Sci. Rep. 2013, 3, 3514.

(23) Mofokeng, J. P.; Luyt, A. S.; Tábi, T.; Kovács, J. Comparison of Injection Moulded, Natural Fibre-Reinforced Composites with PP and PLA as Matrices. J. Thermoplast. Compos. Mater. 2012, 25, 927948.

(24) Kumar, S. Selective Laser Sintering/Melting. In Comprehensive Materials Processing; Hashmi, S., Van Tyne, C. J., Batalham, G. F., Yilbas, B. E., Eds.; Elsevier: Amsterdam, 2014; pp 93-134. 